Document downloaded from:

http://hdl.handle.net/10251/180741

This paper must be cited as:

Latorre, J.; Mollà-Casanova, S.; Salinas, B.; Borrego, A.; Alcañiz Raya, ML.; Colomer, C.; Llorens Rodríguez, R. (2019). Multi-touch-based assessment of hand mobility, dexterity and function. Preliminary study of validity, reliability and sensitivity to upper limb impairment severity in individuals with stroke. IEEE. 1-6. https://doi.org/10.1109/ICVR46560.2019.8994584

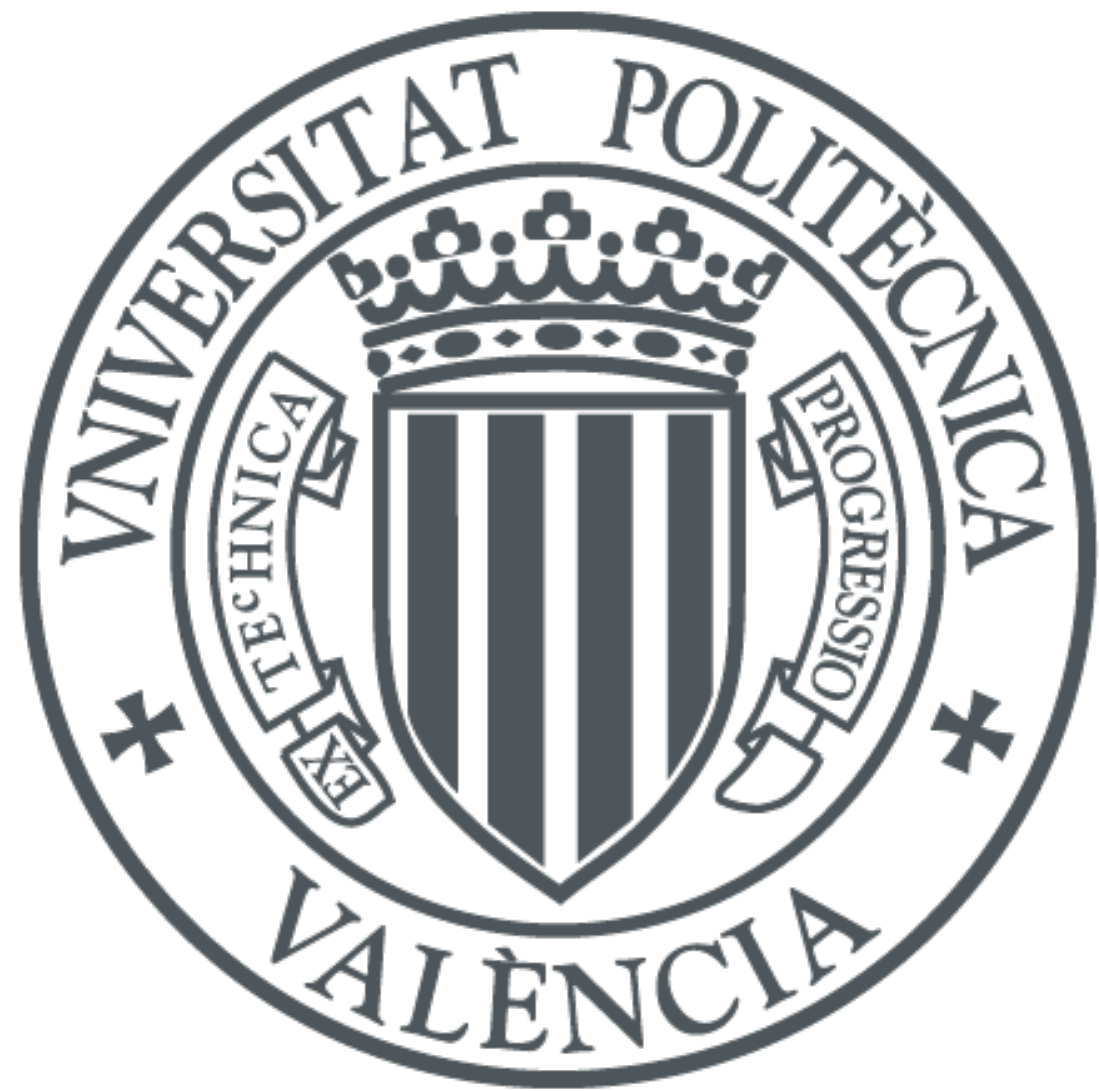

The final publication is available at

https://doi.org/10.1109/ICVR46560.2019.8994584

Copyright IEEE

Additional Information 


\section{Multi-touch-based assessment of hand mobility, dexterity and function. Preliminary study of validity, reliability and sensitivity to upper limb impairment severity in individuals with stroke.}

\author{
Jorge Latorre $^{1,2}$, Sara Mollà-Casanova ${ }^{1}$, Bárbara Salinas ${ }^{1}$, Adrián \\ Borrego $^{1}$, Mariano Alcañiz ${ }^{1}$, Roberto Llorens ${ }^{1,2}$ \\ ${ }^{1}$ Neurorehabilitation and Brain Research Group, Instituto \\ Interuniversitario de Investigación en Bioingeniería. \\ Universitat Politècnica de València. \\ Valencia, Spain. \\ jlatorre@i3b.upv.es
}

\author{
Carolina Colomer ${ }^{2}$ \\ ${ }^{2}$ NEURORHB. Servicio de Neurorrehabilitación de Hospitales \\ Vithas. \\ Valencia, Spain
}

\begin{abstract}
Impairments of the upper limb function are among the most common and disabling sequelae after stroke, and their rehabilitation poses a major challenge for current physical and occupational therapy interventions. While restoration of certain degree of proximal and global movements and function is expected, the recovery of premorbid hand mobility and dexterity is less likely to occur. Although great efforts are usually made to rehabilitate these skills, with customized particular and analytic exercises, their assessment is rarely made with the same level of specificity. In general, hand and finger mobility and functionality are indirectly assessed in the clinic with standardized clinical scales and tests that require the use of these skills to perform some tasks. Although these scales are easy to administer, they can present poor accuracy, be biased, and do not allow for isolated assessment of joints and movements. Multi-touch technology enables interaction with electronic devices, such as smartphones and tablets, with on-screen finger touches. Although there is a very limited number of studies that investigate the potential of this technology to rehabilitate hand mobility and dexterity, the use of this technology for assessment of these skills remains unexplored. This study evaluates the feasibility of a multi-touchbased assessment tool (app) of hand mobility and dexterity in a sample of post-stroke survivors. Our results provide preliminary evidence that this technology can be used to design valid and reliable instruments for assessing hand mobility and dexterity that, in addition, are sensitive to the severity of the motor impairment of the upper limb after stroke, which could complement conventional clinical assessment.
\end{abstract}

Keywords-hand mobility, hand dexterity, assessment, stroke, validity, upper limb, tablet, multi-touch technology, app.

\section{INTRODUCTION}

Among the wide motor alterations after a stroke, impairments of the upper limb function represent one of the most disabling sequelae for the performance of daily activities and one of the greatest challenges for rehabilitation interventions during the whole rehabilitation process [1]. Up to $55-75 \%$ of individuals who have suffered a stroke still present a deficit of the upper limb function 3-6 months after the injury [2], [3]. Common motor deficits, as hemiparesis, which manifest as a decrease of the strength or partial paralysis in the affected limbs [4], and spasticity, which manifest as an unusual tension or increased muscle tone that causes rigidity in most cases [4], have a major negative impact on both mobility and functionality of the upper limbs [5], [6]. The intrinsic difficulty to recover full function of the upper extremities can be partially explained by the great complexity of arm-hand function, which includes grasping, holding, pointing, and manipulating objects, and involve coordination of multiple joints, from the shoulder to the fingers. The recovery of the functionality seems to follow a common pattern, with gross and proximal movements presenting better prognosis, and fine and distal movements being less likely to achieve full recovery. Hand mobility and dexterity, the ability to move and coordinate joint movements of the hand executed by muscles innervated by radial, ulnar and median nerves, is a paradigmatic example of the former. Full recovery of hand mobility and dexterity is difficult to achieve, as it requires fast and accurate coordination of gross and fine voluntary movements, which are developed through lifetime as a result of long-term learning, training, and experience.

For the same reasons, assessment of hand mobility and dexterity is also a difficult task. Clinical evaluation of hand mobility is usually performed with goniometers. Clinical evaluation of hand dexterity is usually indirectly done using conventional clinical assessment tools and tests of upper limb function that involve certain degree of gross and fine hand dexterity. Although clinical scales are usually easy and quick to administer, they can be biased and, more importanly, only provide overall measures of upper limb function that do not allow complete evaluation of the hand mobility and function.

Different technological solutions have been proposed to overcome these limitations.

Robotic devices [7] have been shown to be effective at assessing hand function in hemiplegic individuals with chronic stroke. However, these devices are commonly expensive and require a dedicated space in the clinic. 
Multi-touch technology, as that present in current smartphones and tablets, allows for very precise detection of finger touches and hand gestures on a capacitive screen. This feature, together with their portability and low-cost, have motivated the use of these electronic devices in a small number of studies on hand dexterity. These preliminary studies proved the usability of multi-touch technology on individuals with stroke [8][9] and identified worse performance on this population in comparison to healthy of different age [9]. Although these studies provide preliminary evidence of the potential of multi-touch technology to facilitate interaction with this technology on individuals poststroke, there is no previous report on its potential for assessment of hand mobility and function.

The objective of this study was threefold: first, to determine the convergent validity of a multi-touch-based assessment tool of hand mobility and dexterity with standardized clinical tests on a sample of individuals with stroke; second, to determine its inter-rater reliability, and finally, to determine whether the assessment tool is able to classify participants according to the severity of their impairment.

\section{METHODS}

\section{A. Participants}

Participants were recruited from the long-term stroke management program of Vithas Valencia al Mar Hospital (València, Spain) and Vithas Aguas Vivas Hospital (Carcaixent, Spain). The inclusion criteria to participate in the study were: 1) ischemic or hemorrhagic stroke diagnosed by CT or MR imaging; 2) lack of severe hypertonia that prevented interaction, as defined by scores in the Modified Ashworth Scale below 3; 3) active movement of distal joints, as defined by scores in Medical Research Council Scale for Muscle above 1; and 4) fairly good cognitive condition, as defined by scores in the Mini-Mental State Examination above 23. Candidates were excluded if they had impaired comprehension that hinder sufficient understanding of the instructions, as defined by scores in the Mississippi Aphasia Screening Test scores below 45, and severe visual or auditory deficits that prevent visualization of the instruments. The study was approved by the Institutional Review Board of the Neurorehabilitation and Brain Injury Service of Vithas Hospitals. Written consent was obtained from all of the subjects who satisfied the inclusion criteria and accepted to participate in the study.

\section{B. Instrumentation}

A dedicated assessment tool was programmed for both Android and Windows operating systems. The operation of the application, however, is analogous. The interface was designed to be as simple as possible (Fig. 1).

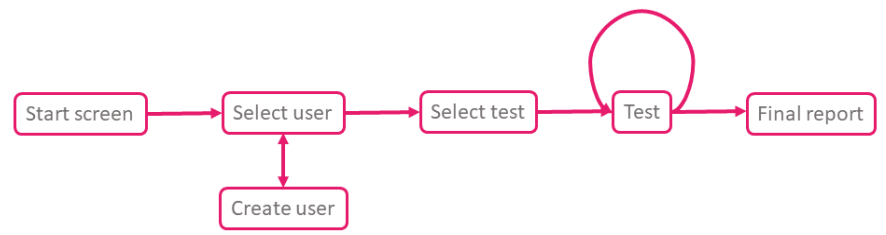

Fig. 1. Flowchart of the hand dexterity assessment tool.

A home screen provides basic information about the tool and allows for basic configuration, as changing the language settings. The next screen allows for selecting an existing user or creating a new one. Once a user is created his/her data are stored and will be available for future assessments unless they are voluntarily deleted. The same screen allows starting a new assessment or checking the results of previous assessments. If a new assessment is selected, the user must choose the hand (left/right) under assessment and, in the next screen, which tests from a total of six are included in the assessment. The selected tests are sequentially executed. Before each test, the application provides a brief description of the exercise and a visual animation of the movement to be performed. During the test visual feedback is provided of each detected touch on the screen. All of the tests begin after a 3 -second countdown and an indication of "Go!". At the end of the assessment, the tool provides basic information of the results and stores the raw data locally for further analysis if desired. A description of the tests is provided below.

\section{1) Tapping}

This test evaluates the number of index finger touches on the screen that can be performed in 10 seconds (Fig. 2). The output parameters of this test are the number of touches, and the reaction time, which corresponds to the time from the start of the test until the first touch detected.

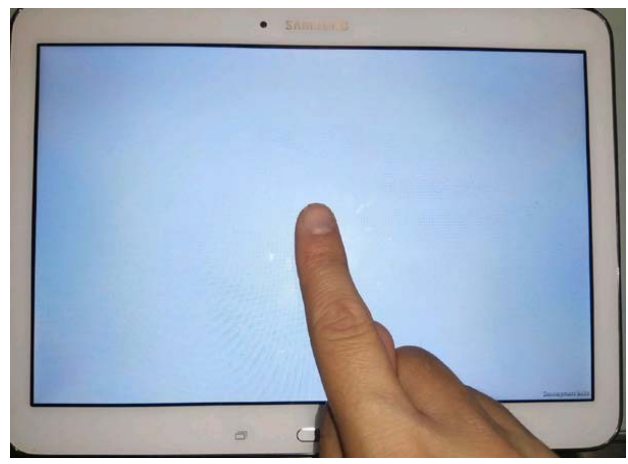

Fig. 2. Tapping test.

2) Flexion and extension of isolated metacarpophanlangeal joints

Similar to the tapping test, this test evaluates the number of touches on the screen that can be performed with each finger while maintaining the other fingers in contact with the screen (Fig. 3). If this condition is not satisfied, the number of touches are not taken into account. The output parameters of this test are, analogously, the number of touches and the reaction time for each finger. 


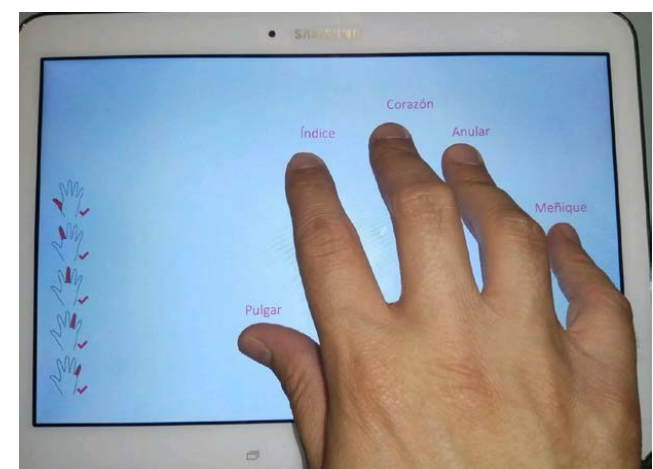

Fig. 3. Flexion and extension of isolated metacarpophanlangeal joints test.

\section{3) Finger pinch range}

This test evaluates the maximum and minimum distance that the thumb and each one of the other fingers can be separated (extension of the metacarpophalangeal and interphalangeal joints) and move closer together (flexion of the metacarpophalangeal and interphalangeal joints) without losing contact with the screen (Fig. 4). Multiple attempts can be made. The output parameters of this test are the minimum and the maximum distance reached.

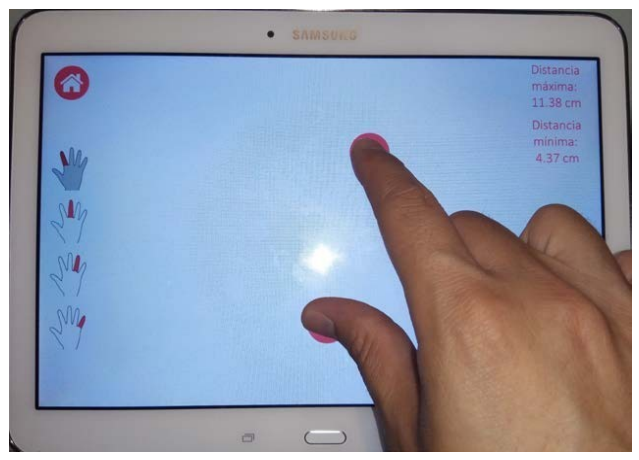

Fig. 4. Finger pinch range test.

\section{4) Hand opening and closing area}

This test evaluates the maximum and minimum area defined by extending and flexing the fingers (Fig. 5). Analogously to the previous test, multiple repetitions can be performed. The output parameters of this test are the minimum and maximum area reached.

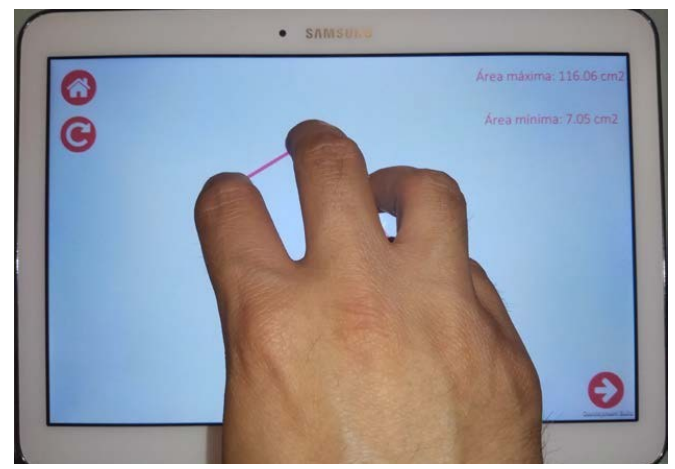

Fig. 5. Hand opening and closing area test.

\section{5) Oculo-manual coordination control}

This test evaluates the ocular and manual tracking and reaching of 32 visual targets arranged on a $4 \times 8$ grid (Fig. 6). Reaches can be performed with the fingers or a touchscreen pencil in the shortest possible time. The output parameters of this test are the time to touch all the targets and the number of off-target touches.

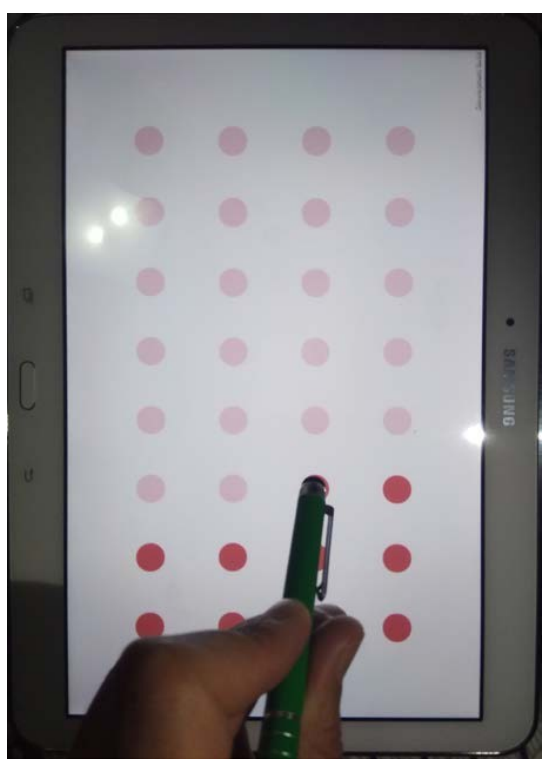

Fig. 6. Oculo-manual coordination control test.

\section{Procedure}

All the participants were assessed with three standardized clinical scales and tests and with the developed multi-touchbased tool. Sixteen participants were assessed by two different experimenter within the same day, the experimenter is in charge of explaining the test to the participant. During the assessment, the participants were seated in a chair and their hand were positioned in a convenience position for the test without an assistive device. All the exercises presented in the multi-touch-based tool were performed once, but the oculomanual coordination test, which was performed twice (with a touchscreen pencil and with the fingers). Clinical assessment included the Upper Extremity subscale of the Fugl-Meyer Assessment Scale, the Box and Block Test, and the Nine Hole Peg Test. A 12" tablet, the Chuwi Hi12 (Chuwi Technology, Shenzhen, China), running the Android version of the multitouch-based test was used. All the assessments were performed for each participant within the same day. The duration of a complete assessment was approximately 30 minutes.

\section{Data analysis}

Non-normal distribution of the data was confirmed with Shapiro-Wilk testing. Spearman correlation was used to investigate possible associations between the output parameters of each test of the multi-touch-based tool and variables of the conventional clinical scales and tests.

The inter-observer reliability of the multi-touch-based measures was determined with a repeated measures analysis of 
variance to calculate the intraclass correlation coefficient (ICC) [10].

Finally, participants were categorized according to the severity of their upper limb function with the Fugl-Meyer Assessment Scale as mild (scores between 47 and 66) or moderate (scores between 19 and 47). A Student's t-test was used to compare multi-touch-based measures between both groups. Homoscedasticity was previously checked (Levene test), using the Statterthwaite approach in case of noncompliance.

The SPSS v22 (SPSS Inc., Chicago, IL, USA) was used to perform the statistical analysis.

\section{RESULTS}

\section{A. Participants}

A convenient sample of forty-five individuals with stroke, 18 women and 27 men, were enrolled and took part in this study. Participants presented a mean age of $54.9 \pm 14.6$ years old and a time since injury of $23.7 \pm 28.5$ months. Etiology of the participants included hemorrhagic $(n=21)$ and ischemic stroke $(n=24)$. Brain injuries affected the left $(n=25)$, right $(n=14)$, and both hemispheres $(n=2)$, and the brainstem $(n=4)$. The mild impairment group consisted of 26 participants and moderate impairment group consisted of 19 participants.

\section{B. Convergent validity between clinical instruments and the mutitouch-based tool}

Significant interactions of different strength emerged between the variables of the multi-touch-based tool and clinical instruments.

Interactions with the Fugl-Meyer Assessment Scale were mostly moderate for all the variables but for the minimum index and middle finger pinch and minimum palmar area, which were poor or non-significant (Table I).

TABLE I. CORRELATIONS BETWEEN THE MULTI-TOUCH-BASED VARIABLES AND THE FUGL-MEYER ASSESSMENT SCALE.

\begin{tabular}{|c|c|c|c|c|c|}
\hline Variables & $\begin{array}{c}\text { Shoulder, } \\
\text { elbow, } \\
\text { forearm }\end{array}$ & Wrist & Hand & $\begin{array}{c}\text { Coordi } \\
\text { nation/ } \\
\text { speed }\end{array}$ & Total \\
\hline Taps $^{1}$ & $0.41 *$ & $0.56^{* *}$ & $0.65 * *$ & $0.60 * *$ & $0.63^{* *}$ \\
\hline Thumb touches ${ }^{2}$ & $0.64 * *$ & $0.73 * *$ & $0.52 * *$ & $0.50 * *$ & $0.79 * *$ \\
\hline Index finger touches ${ }^{2}$ & $0.59 * *$ & $0.70 * *$ & $0.54 * *$ & $0.38^{*}$ & $0.74 * *$ \\
\hline Ring finger touches ${ }^{2}$ & $0.61 * *$ & $0.65^{* *}$ & $0.54 * *$ & $0.46^{*}$ & $0.69^{* *}$ \\
\hline Pinky finger touches ${ }^{2}$ & $0.63 * *$ & $0.74 * *$ & $0.50 * *$ & $0.49 *$ & $0.77 * *$ \\
\hline Min. index finger pinch ${ }^{3}$ & -0.06 & -0.15 & -0.27 & -0.07 & -0.14 \\
\hline Max. index finger pinch ${ }^{3}$ & $0.33^{*}$ & $0.39 *$ & $0.32 *$ & $0.34 *$ & $0.43^{*}$ \\
\hline Min. middle finger pinch $^{3}$ & -0.13 & -0.29 & $-0.41^{*}$ & -0.31 & $-0.32 *$ \\
\hline Max. middle finger pinch $^{3}$ & $0.33^{*}$ & $0.51^{* *}$ & $0.34^{*}$ & 0.22 & $0.44^{*}$ \\
\hline Min. ring finger pinch $^{3}$ & $-0.36^{*}$ & $-0.53 * *$ & $-0.54 * *$ & $-0.33 *$ & $-0.56 * *$ \\
\hline Max. ring finger pinch $^{3}$ & $0.38 *$ & $0.47 *$ & 0.30 & 0.32 & $0.48^{*}$ \\
\hline Min. pinky finger pinch ${ }^{3}$ & $-0.53^{* *}$ & $-0.55^{* *}$ & $-0.37 *$ & -0.23 & $-0.58 * *$ \\
\hline
\end{tabular}

\begin{tabular}{|c|c|c|c|c|c|}
\hline Max. pinky finger pinch ${ }^{3}$ & $0.44 *$ & $0.52 * *$ & $0.54^{* *}$ & $0.46^{*}$ & $0.58 * *$ \\
\hline Min. palmar area ${ }^{4}$ & -0.08 & -0.23 & -0.09 & -0.19 & -0.17 \\
\hline Max. palmar area ${ }^{4}$ & 0.26 & $0.51 * *$ & $0.57^{* *}$ & $0.47^{*}$ & $0.52 * *$ \\
\hline $\begin{array}{l}\text { Oculo-manual } \\
\text { coordination (touchscreen } \\
\text { pencil) }\end{array}$ & $0.38 *$ & $0.46^{*}$ & $0.31^{*}$ & $0.54 * *$ & $0.45 *$ \\
\hline $\begin{array}{l}\text { Oculo-manual } \\
\text { coordination (finger) })^{5}\end{array}$ & $0.38 *$ & $0.49 *$ & $0.42 *$ & $0.61 * *$ & $0.51 * *$ \\
\hline
\end{tabular}

${ }^{1}$ : Tapping test. ${ }^{2}$ : Flexion and extension of isolated metacarpophanlangeal joints test. ${ }^{3}$ : Finger pinch range. ${ }^{4}$ : Hand opening and closing test. ${ }^{5}$ : Oculo-manual coordination test. *: $p<0.05 .{ }^{* *}$ : $p<0.01$.

Significant interactions with the Box and Block Test and the Nine Hole Peg Test were detected in almost all measures of the multi-touch-based tests but for the minimum palmar area (Table II).

TABLE II. CORRELATIONS BETWEEN THE MULTI-TOUCH-BASED VARIABLES AND the BOX AND BlOCK TeSt AND THE NINE Hole PEG TEST

\begin{tabular}{|c|c|c|}
\hline Variables & $\begin{array}{c}\text { Box and } \\
\text { Block Test }\end{array}$ & $\begin{array}{c}\text { Nine Hole } \\
\text { Peg Test }\end{array}$ \\
\hline Taps $^{1}$ & $0.70 * *$ & $-0.65^{* *}$ \\
\hline Thumb touches ${ }^{2}$ & $0.77 * *$ & $-0.74 * *$ \\
\hline Index finger touches ${ }^{2}$ & $0.72 * *$ & $-0.77 * *$ \\
\hline Ring finger touches ${ }^{2}$ & $0.75 * *$ & $-0.84 * *$ \\
\hline Pinky finger touches ${ }^{2}$ & $0.72 * *$ & $-0.87 *$ \\
\hline Min. index finger pinch $^{3}$ & $-0.91 * *$ & 0.30 \\
\hline Max. index finger pinch $^{3}$ & $0.51 * *$ & $-0.52 * *$ \\
\hline Min. middle finger pinch ${ }^{3}$ & $-0.44 *$ & $0.49 *$ \\
\hline Max. middle finger pinch $^{3}$ & $0.48^{*}$ & $-0.42 *$ \\
\hline Min. ring finger pinch $^{3}$ & $-0.44^{*}$ & $0.40^{*}$ \\
\hline Max. ring finger pinch $^{3}$ & $0.50 * *$ & $-0.47 *$ \\
\hline Min. pinky finger pinch ${ }^{3}$ & $-0.59 * *$ & $0.64 * *$ \\
\hline Max. pinky finger pinch ${ }^{3}$ & $0.60 * *$ & -0.30 \\
\hline Min. palmar area ${ }^{4}$ & -0.22 & 0.10 \\
\hline Max. palmar area ${ }^{4}$ & $0.64 * *$ & $-0.37 *$ \\
\hline $\begin{array}{l}\text { Oculo-manual coordination (touchscreen } \\
\text { pencil) }^{5}\end{array}$ & $0.55 * *$ & -0.29 \\
\hline Oculo-manual coordination (finger) ${ }^{5}$ & $0.68 * *$ & -0.27 \\
\hline
\end{tabular}

${ }^{1}$ : Tapping test. ${ }^{2}$ : Flexion and extension of isolated metacarpophanlangeal joints test. ${ }^{3}$ : Finger pinch range. ${ }^{4}$ : Hand opening and closing test. ${ }^{5}$ : Oculo-manual coordination test. $*$ : $p<0.05$. ${ }^{* *}$ : $\mathrm{p}<0.01$

\section{Inter-observer reliability}

All the variables reached good to excellent reliability, but the maximum index finger pinch, the minimum middle finger pinch, the maximum ring finger pinch, and the minimum pinky finger pinch, which were poor to moderate [10] (Table III). 
TABLE III. INTER-OBSERVER RELIABILITY

\begin{tabular}{|c|c|}
\hline Variables & ICC \\
\hline Taps $^{1}$ & $0.96^{*}$ \\
\hline Thumb touches ${ }^{2}$ & $0.87 *$ \\
\hline Index finger touches ${ }^{2}$ & $0.84 *$ \\
\hline Ring finger touches ${ }^{2}$ & $0.94 *$ \\
\hline Pinky finger touches ${ }^{2}$ & $0.83^{*}$ \\
\hline Min. index finger pinch $^{3}$ & $0.81 *$ \\
\hline Max. index finger pinch $^{3}$ & 0.14 \\
\hline Min. middle finger pinch $^{3}$ & 0.34 \\
\hline Max. middle finger pinch $^{3}$ & $0.73 *$ \\
\hline Min. ring finger pinch $^{3}$ & $0.90 *$ \\
\hline Max. ring finger pinch $^{3}$ & 0.54 \\
\hline Min. pinky finger pinch ${ }^{3}$ & 0.49 \\
\hline Max. pinky finger pinch ${ }^{3}$ & $0.70^{*}$ \\
\hline Min. palmar area ${ }^{4}$ & $0.84 *$ \\
\hline Max. palmar area ${ }^{4}$ & $0.71 *$ \\
\hline $\begin{array}{l}\text { Oculo-manual coordination } \\
\text { (touchscreen pencil) }^{5}\end{array}$ & $0.85^{*}$ \\
\hline $\begin{array}{l}\text { Oculo-manual coordination } \\
\text { (finger) }^{5}\end{array}$ & $0.96^{*}$ \\
\hline
\end{tabular}

${ }^{1}$ : Tapping test. ${ }^{2}$ : Flexion and extension of isolated metacarpophanlangeal joints test. ${ }^{3}$ : Finger pinch range. ${ }^{4}$ : Hand opening and closing test. ${ }^{5}$ : Oculo-manual coordination test. ${ }^{*}: \mathrm{p}<0.05$.

\section{Ability to differentiate levels of severity}

Some of multi-touch-based measures showed significant differences between participants with mild and moderate severity (Table IV).

TABLE IV. DESCRIPTIVE RESULTS OF MULTI-TOUCH-BASED VARIABLES AND THE SEVERITY CATEGORIZATION OF THE PARTICIPANTS

\begin{tabular}{|c|c|c|c|}
\hline Variables & $\begin{array}{c}\text { Mild } \\
\text { severity }\end{array}$ & $\begin{array}{c}\text { Moderate } \\
\text { severity }\end{array}$ & $\mathbf{p}$ \\
\hline Taps $^{1}$ & $37.16(15.53)$ & $22.62(12.72)$ & $<0.05$ \\
\hline Thumb touches ${ }^{2}$ & $30.81(12.05)$ & $10.57(9.86)$ & $<0.05$ \\
\hline Index finger touches ${ }^{2}$ & $33.38(13.81)$ & $11.5(11.43)$ & $<0.05$ \\
\hline Ring finger touches ${ }^{2}$ & $30.5(13.18)$ & $14.5(9.75)$ & $<0.05$ \\
\hline Pinky finger touches ${ }^{2}$ & $26.1(10.89)$ & $7.2(7.89)$ & NS \\
\hline Min. index finger pinch ${ }^{3}$ & $1.73(1.2)$ & $2.66(2.93)$ & NS \\
\hline Max. index finger pinch ${ }^{3}$ & $12.16(1.88)$ & $9.94(2.56)$ & $<0.05$ \\
\hline Min. middle finger pinch $^{3}$ & $1.52(0.85)$ & $2.8(2.71)$ & NS \\
\hline Max. middle finger pinch ${ }^{3}$ & $13.58(2.25)$ & $11.47(1.62)$ & $<0.05$ \\
\hline Min. ring finger pinch ${ }^{3}$ & $1.36(0.51)$ & $4.52(4.04)$ & NS \\
\hline Max. ring finger pinch ${ }^{3}$ & $14.38(1.95)$ & $12.13(2.78)$ & NS \\
\hline Min. pinky finger pinch ${ }^{3}$ & $1.83(1.2)$ & $2.5(1.19)$ & NS \\
\hline Max. pinky finger pinch ${ }^{3}$ & $14.17(2.78)$ & $15.94(19.6)$ & NS \\
\hline Min. palmar area ${ }^{4}$ & $2.82(1.33)$ & $2.58(0.71)$ & NS \\
\hline Max. palmar area ${ }^{4}$ & $90.24(22.82)$ & $59.19(27.5)$ & $<0.05$ \\
\hline
\end{tabular}

\begin{tabular}{|l|c|c|c|}
\hline $\begin{array}{l}\text { Oculo-manual coordination } \\
\text { touchscreen pencil) }^{5}\end{array}$ & $18,5(9,86)$ & $8,25(4,37)$ & NS \\
\hline Oculo-manual coordination (finger) $^{5}$ & $29.16(7.37)$ & $23.83(8.82)$ & NS \\
\hline
\end{tabular}

The data are expressed in mean (standard deviation). ${ }^{1}:$ Tapping test. ${ }^{2}$ : Flexion and extension of isolated metacarpophanlangeal joints test. ${ }^{3}$ : Finger pinch range. ${ }^{4}$ : Hand opening and closing test. ${ }^{5}$ : Oculomanual coordination test. NS: non-significance.

\section{DISCUSION}

This is the first study that presents a multi-touch-based tool for assessing hand mobility and dexterity and evaluates its validity in people with stroke. Our results suggest that the tool could be a valid and reliable instrument for assessing hand mobility and dexterity and, in addition, it is able to differentiate levels of severity of upper limb function after stroke.

Although multi-touch technology has become worldwide available thanks to the popularity of smartphones and tablets, a few multi-touch apps exist for neurorehabilitation [11]. Among them, only one study aimed to evaluate drawings made by individuals post-stroke in order to predict their recovery [12]. Unfortunately, drawing requires fine motor skills that could restrict the use of this application to individuals with mild to low hand function impairment. Mobility of the fingers, as that required for drawing, could be a challenge for interacting with mobile applications after stroke. The multi-touch-based tool presented in this paper assesses not only gross motor function but also evaluates mobility of each finger as well as the overall hand mobility, and includes assessment of coordination and hand dexterity.

Measures of the multi-touch-based tool show multiple significant correlations with measures of the Fugl-Meyer Assessment Scale, the Box and Block Test, and the Nine Hole Peg Test, which had variable strength, ranging from poor to excellent. Poor correlations, as those obtained for the minimum index finger pinch, could be due to the fact that those movements are not involved in the clinical scales or they do not interfere in the score. However, besides strength of the correlations, importance of these interactions lies on the fact that their sign were coherent for all variables. For instance, higher number of touches in the Tapping test was related to better scores in the clinical scales (higher in the Fugl-Meyer Assessment Scale and Box and Block Test, and lower in the Nine Hole Peg Test), which were related to smaller finger pinch values. These results suggest that the multi-touch-based tool and the clinical scales were in fact related.

Among the 17 variables calculated by the multi-touchbased tool, 13 of them showed good to excellent interobserver reliability. Interestingly, some of these variables had comparable results to the Fugl-Meyer Assessment Scale $(\mathrm{ICC}=0.99)$ [13], the Box and Block Test $(\mathrm{ICC}=0.98)$ [14], and the Nine Hole Peg Test (ICC=0.85) [14], which highlight reliability of the multi-touch-based tool. Importance of these results is that they allow for small minimum detectable changes, which guarantee that the variations detected by the multi-touch-based variables are due to changes in mobility and hand dexterity level, and not because of standard error of the measure, protocol or the instrument [15]. 
Some of multi-touch-based measures successfully classified participants according to their level of severity, according to the Fugl-Meyer Assessment Scale [16]. Individuals with mild functional severity could perform most of the tests of the multi-touch-based tool. In contrast, the group of participants with moderate functional severity showed greater difficulty to perform the most demanding tests, and had lower scores. Importance of properly identifying the levels of severity is that they have been used to define general treatment guidelines.

In conclusion, the multi-touch-based tool is a valid and reliable tool that is able to differentiate levels of severity of the upper limb function after stroke. Potential advantages of the multi-touch-based tool over conventional clinical scales and test are that it could be more accurate and objective, results are self-explanatory and easy to interpret, and it does not require specific and expensive materials.

\section{CONCLUSIONS}

The conclusions of the present study are: first, the multitouch-based tool is a valid instrument for assessing hand mobility and dexterity in subjects with stroke; second, it has good to excellent inter-rater reliability; and finally, it is sensitive to the impairment severity of the upper limb function.

\section{ACKNOWLEDGMENT}

This study was partially funded by project VALORA, grant 201701-10 of the Fundació la Marató de la TV3 (Barcelona, Spain), grant BES-2014-068218 of the Ministerio de Economía y Competitividad of Spain (Madrid, Spain), and grant "Ayuda a Primeros Proyectos de Investigación (PAID-06-18), Vicerrectorado de Investigación, Innovación y Transferencia de la Universitat Politècnica de València, València, Spain"

\section{REFERENCES}

[1] J. V Basmajian, "The Winter of Our Discontent: Breaking Intolerable Time Locks for Stroke Survivors," Arch Phys Med Rehabil, vol. 70, p. 92, 1989.

[2] A. Henderson, N. Korner-Bitensky, and M. Levin, "Virtual Reality in Stroke Rehabilitation: A Systematic Review of its Effectiveness for Upper Limb Motor Recovery,” Top. Stroke Rehabil., 2007.

[3] T. S. Olsen, "Arm and leg paresis as outcome predictors in stroke rehabilitation," Stroke, 1990.
[4] W. Kakuda et al., "Anti-spastic effect of low-frequency rTMS applied with occupational therapy in post-stroke patients with upper limb hemiparesis," Brain Inj., 2011.

[5] C. E. Levy, D. S. Nichols, P. M. Schmalbrock, P. Keller, and D. W. Chakeres, "Functional MRI evidence of cortical reorganization in upper-limb stroke hemiplegia treated with constraint-induced movement therapy," Am. J. Phys. Med. Rehabil., 2001.

[6] J. Broeren, M. Rydmark, and K. S. Sunnerhagen, "Virtual reality and haptics as a training device for movement rehabilitation after stroke: A single-case study," Arch. Phys. Med. Rehabil., 2004.

[7] E. Otaka et al., "Clinical usefulness and validity of robotic measures of reaching movement in hemiparetic stroke patients," J. Neuroeng. Rehabil., 2015.

[8] D. Rand, T. Schejter-Margalit, I. Dudkiewicz, R. Kizony, G. Zeilig, and R. Kizony, "The use of the iPad for poststroke hand rehabilitation; A pilot study," in 2013 International Conference on Virtual Rehabilitation (ICVR), 2013, pp. 109-113.

[9] R. Kizony, G. Zeilig, I. Dudkiewicz, T. Schejter-Margalit, and D. Rand, "Tablet apps and dexterity: Comparison between 3 age groups and proof of concept for stroke rehabilitation," J. Neurol. Phys. Ther., 2016.

[10] P. E. Shrout and J. L. Fleiss, "Intraclass correlations: Uses in assessing rater reliability,” Psychol. Bull., 1979.

[11] M. T. Sánchez Rodríguez, S. Collado Vázquez, P. Martín Casas, and R. Cano de la Cuerda, "Apps en neurorrehabilitación. Una revisión sistemática de aplicaciones móviles,” Neurología, 2015.

[12] K. Grünich, V. Garcia-Hoyos, C. Stinear, S. Ackerley, J. Tiemensma, and E. Broadbent, "Kinematic measures of brain drawings are associated with illness perceptions in people with stroke," Int. Psychogeriatrics, 2016.

[13] P. Duncan et al., "A randomized, controlled pilot study of a homebased exercise program for individuals with mild and moderate stroke," Stroke, 1998.

[14] T. J. H. Bovend'Eerdt, H. Dawes, H. Johansen-Berg, and D. T. Wade, "Evaluation of the Modified Jebsen Test of Hand Function and the University of Maryland Arm Questionnaire for Stroke," Clin. Rehabil., 2004.

[15] J. P. Weir, "Quantifying test-retest reliability using the intraclass correlation coefficient and the SEM," Journal of Strength and Conditioning Research. 2005.

[16] M. L. Woodbury, C. A. Velozo, L. G. Richards, and P. W. Duncan, "Rasch analysis staging methodology to classify upper extremity movement impairment after stroke," Arch. Phys. Med. Rehabil., 2013. 